九州大学学術情報リポジトリ

Kyushu University Institutional Repository

Reproduction of Ulvaceous Algae with Special Reference to the Periodic Fruiting : IV. Fruiting on Successive Days and Growth Rate of Ulva pertusa

Okuda, Takeo

Fisheries Laboratory, Faculty of Agriculture, Kyushu University

Yamasaki, Makoto

https://doi.org/10.5109/23868

出版情報 : 九州大学大学院農学研究院紀要. 32 (1/2)，pp.69-77，1987-12. Kyushu University バージョン：

権利関係 : 


\title{
Reproduction of Ulvaceous Algae with Special R eference to the Periodic Fruiting IV. Fruiting on Successive Days and Growth R ate of Ulva pertusa
}

\author{
Takeo 0 kuda* and M akoto $Y$ amasaki \\ Fisheries Laboratory, Faculty of Agriculture, \\ Kyushu University 46-04, Fukuoka 812 \\ (Received July 10, 1987)
}

\begin{abstract}
Fertile blades of Ulva pertusa appeared during a neap tide series at Tsuyazaki, as was reported previously. In 1974, however, fertile sporophytes were observed through the series even after they were outnumbered by fertile gametophytes. Each blade liberated swarmers not fortnightly, but several times during a neap tide series, Fruiting on 2 or more successive days was quite common, and 2 blades out of 31 were observed to fruit 5 successive days. Tagging blades with vinyl spaghetti was effective to follow each one at habitat. Fruiting interval changed easily when a blade was put in an aquarium with no emersion. Fruiting on successive days is common and a 3-6-day interval was also dominant, Growth rate was high enough to cover the loss in length due to fruiting on the preceding day. One blade was found to be sterile and to have a very high growth rate reaching 12.5 times lengthwise in 20 days. Distal area had a higher rate, while basal area did not elongate.
\end{abstract}

\section{INTRODUCTION}

The senior author reported on the reproduction of Ulva pertusa from a standpoint of rhythmicity visiting Okayama and the Noto Peninsula other than Tsuyazaki, northern Kyushu, and showed that fruiting followed either a semilunar (Sawada and Watanabe, 1974 ; Okuda, 1975) or a nonlunar cycle (Okuda, 1984). As fertile blades appeared during neap tides both at Tsuyazaki and Okayama, he was convinced that each blade became fertile around every 14 days. Fertile blades were, however, very much distinct and large in number on 5 or more consecutive days at this fruiting period except in wet weather, and he began to wonder if fertile blades were too many to produce swarmers fortnightly. As the right method had not occurred to him to mark each blade, previous observations covered general colonies and it was unfeasible to follow each blade in fruiting.

In 1974 he chanced to observe a blade liberate gametes on 2 straight days. As this clearly demonstrated that an Ulva blade could liberate swarmers at least 2 times during a neap tide series, he came to believe that it was essential to make observations on each blade under natural conditions. Finding vinyl spaghetti for marking blades separately, he conducted observations with success and found that some blades became fertile 4 or 5 times in a neap tide series.

Although Ulva blades repeated reproduction quite often, they did not seem to become small in size. The authors then made observations on fruiting and recorded

* Formerly Takeo Sawada 
their sizes in aquaria. Details are given in this paper on frequent reproduction and a high growth rate of this alga.

\section{MATERIAL AND METHODS}

Daily field observations were made in a May- June period, 1974, on the occurrence of fertile blades of Ulva pertusa in Tsuyazaki, a suburb of Fukuoka, where the Fishery Research Laboratry of Kyushu University is located. The same method as reported before (Sawada and Watanabe, 1974) was employed, and fruiting of sporophytes followed by gametophytes was reconfirmed during each neap tide series.

Along with these observations, some blades were put in glass aquaria and each blade was followed in fruiting and in growth. Aquaria were placed outdoors, and blades were immersed in running seawater.

When fertile blades appeared in June, July, and August, 1976, some of them were tagged with vinyl spaghetti of different colors and were separately followd in fruiting at habitat. Fertile blades have a yellow-brown margin about $1-50 \mathrm{~mm}$ wide, and this zone is not always of the same width depending on blades and even on one blade at its repeated fruiting. Five ranks were set up for this fertile area according to its external appearance, i. e. fertile area is none (0), dotted on the margin (1), big but discontinuous (2), wide and continuous (3), distinct and wide more than $10 \mathrm{~mm}$ (4) (Fig. 1).

During the aquarium culture in 1974, the growth of blades was so rapid that these blades looked too densely populated in each aquarium in a few weeks. The authors then tried to follow growth patterns by clipping each blade into a strip $10 \mathrm{~mm}$ wide with its holdfast, and keeping it underwater three weeks in July of 1976. A whole strip was traced on a sheat of waterproof paper as well as original perforations so that different growth rates at each part might be checked.

\section{RESULTS}

\section{Development of fertile blades}

Finding a six-day periodicity in the fruiting of this alga on the Noto Peninsula (Okuda, 1984), the authors made an investigation again into the development of fertile blades in Tsuyazaki for fear it would be different from the previous report (Sawada and Watanabe, 1974). Daily observations were made during about 3 weeks to cover 2 successive neap tide series. The result, however, turned out to be almost the same as the previous one (Table 1).

Fruiting occurred during neap tides and only a few fertile blades appeared during spring tides. The figure 50 in Table 1 is equivalent to figure 100 in the previous reports representing enormous amount of fertile blades, while figures 49 and under show small amount of such ones. Fertile sporophytes came first to appear on May 12 and 26, 2 days before each quarter of the moon. Fertile gametophytes followed fertile sporophytes and outnumbered the latter on May 15 and 29, the next days of the respective quarters of the moon. Both fertile sporophytes and fertile gametophytes were observed until neap tides were over.

Fruiting on successive days

W hen fertile blades appeared during neap tides, almost all of Ulva colonies at 
Table 1. Rise and fall of fertile plants of Ulva pertusa in Tsuyazaki, northern Kyushu, 1974.

\begin{tabular}{|c|c|c|c|c|c|c|c|}
\hline & \multirow{2}{*}{$\begin{array}{l}\text { Moon's } \\
\text { age }\end{array}$} & \multicolumn{3}{|c|}{ Number of plants examined } & \multirow{2}{*}{$\begin{array}{l}\text { Time of } \\
\text { low water }\end{array}$} & \multirow{2}{*}{$\begin{array}{c}\text { Water level } \\
\text { at low water } \\
(\mathrm{cm})\end{array}$} \\
\hline & & & Totol & Camato & & & \\
\hline \multirow[t]{21}{*}{ May } & 11 & 18.7 & 0 & 0 & 0 & 1847 & 32 \\
\hline & 12 & 19.7 & 50 & 0 & 50 & 724 & 86 \\
\hline & 13 & 20.7 & 44 & 0 & 44 & 813 & 90 \\
\hline & 14 & $21.7 \bigcirc$ & 43 & 20 & 23 & 919 & 92 \\
\hline & 15 & 22.7 & 50 & 31 & 19 & 1037 & 88 \\
\hline & 16 & 23.7 & 50 & 32 & 18 & 1147 & 78 \\
\hline & 17 & 24.7 & 50 & 40 & 10 & 1243 & 64 \\
\hline & 18 & 25.7 & 0 & 0 & 0 & 1328 & 48 \\
\hline & 19 & 26.7 & 0 & 0 & 0 & 1408 & 32 \\
\hline & 20 & 27.7 & 0 & 0 & 0 & 1449 & 17 \\
\hline & 21 & 28.7 & 22 & 22 & 0 & 1530 & 5 \\
\hline & 22 & 0.3 & 4 & 1 & 3 & 1610 & -2 \\
\hline & 23 & 1.3 & 11 & 0 & 11 & 1653 & -6 \\
\hline & 24 & 2.3 & 0 & 0 & 0 & 1739 & -3 \\
\hline & 25 & 3.3 & 0 & 0 & 0 & 1826 & 4 \\
\hline & 26 & 4.3 & 30 & 0 & 30 & 702 & 71 \\
\hline & 27 & 5.3 & 50 & 4 & 46 & 758 & 74 \\
\hline & 28 & $6.3 \bigcirc$ & 50 & 19 & 31 & 902 & 74 \\
\hline & 29 & 7.3 & 50 & 49 & 1 & 1013 & 71 \\
\hline & 30 & 8.3 & 50 & 50 & 0 & 1128 & 63 \\
\hline & 31 & 9.3 & 50 & 40 & 10 & 1233 & 51 \\
\hline \multirow[t]{3}{*}{ June } & 1 & 10.3 & 50 & 28 & 22 & 1327 & 38 \\
\hline & 2 & 11.3 & 32 & 19 & 13 & 1412 & 27 \\
\hline & 3 & 12.3 & 0 & 0 & 0 & 1453 & 10 \\
\hline
\end{tabular}

habitat looked to be in fruiting conditions. As such an appearance continued 5 or 6 days in every neap tide series, the authors were concerned with fortnightly fruiting of each blade. Finding a blade liberate swarmers 2 consecutive days, the authors put some blades in glass aquaria outdoors and indoors, furnishing them with or without running seawater. All blades, including even the ones kept indoors without running seawater, liberated swarmers 2 or more consecutive days. Then observations were made at habitat. When fertile blades appeared, they were ranked by their conditions of fertile areas (Fig. 1), and only ones with ranks 3 and 4 were tagged.

In a period from June 1 to August 7, 1976, a total of 199 blades was tagged with vinyl spaghetti and were daily followed on separately. Sixteen of them were missing on the following day of tagging, and 17 survived just 2 days. Table 2 shows the results of 31 blades tagged on July 3, 4, and 5 . Of 35 blades tagged, 4 were missing on the following day of tagging and 15 survived as of the 10th. Blank spaces in Table 2 are due to dislodgement of blades by wave action or to grazing by Aplysiakurodai (Mollusca). If ranks 3 and 4 are taken for fruiting, it is confirmed that fruiting on successive days is of a general occurrence. Blades numbers 23 and 24 repeated reproduction 5 consecutive days, and number 31 did 4 consecutive days with the rank 4 appearing 3 days. If only frequency is concerned, not necessarily consecutive, 9 blades out of 31 liberated swarmers 4 times or over, or 22 blades liberated swarmers 3 times or over in this neap tide series. 


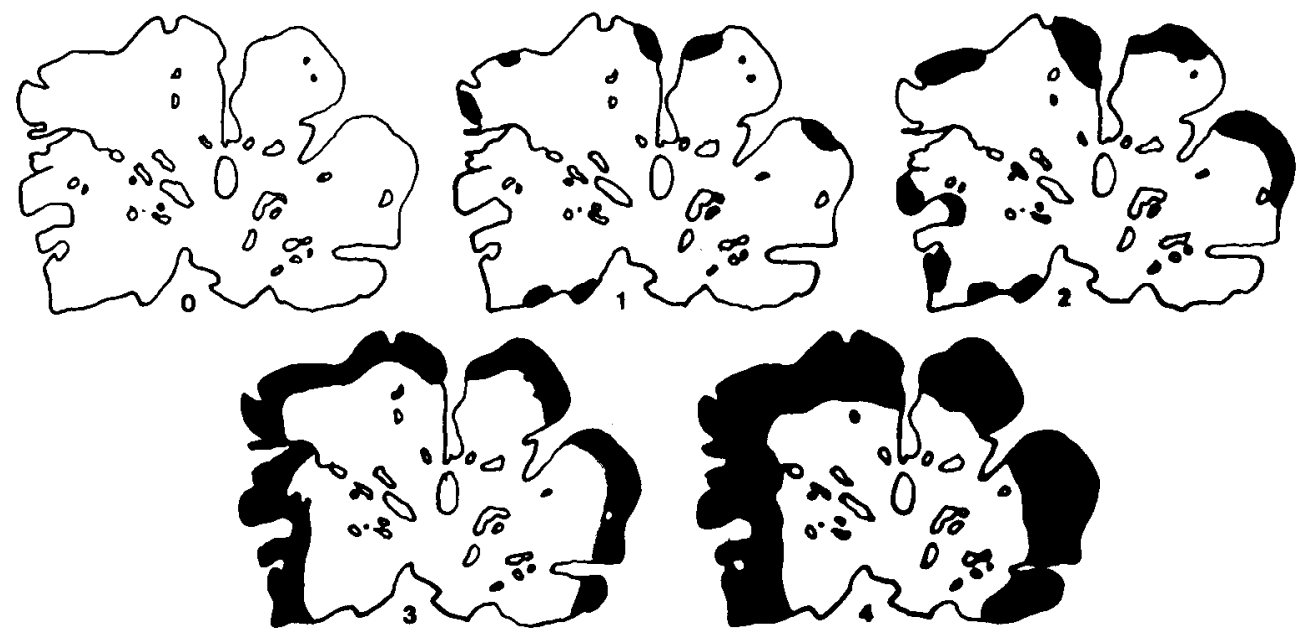

Fig. 1. Five ranks visually judged in the fruiting of Ulva pertusa. Fruiting does not necessarily proceed 0 to 4 in order.

Table 2. Frequent and sometimes successive-day fruiting of Ulva pertusa at habitat during a neap tide series in July, 1976, represented by ranks as in Fig. 1.

\begin{tabular}{ccccccccc}
\hline & \multicolumn{1}{c}{ Date } \\
\cline { 2 - 8 } $\begin{array}{c}\text { Plant } \\
\text { no. }\end{array}$ & 3 & 4 & 5 & 6 & 7 & 8 & 9 & 10 \\
& & & 0 & & & & & \\
\hline 1 & 3 & 0 & 0 & 2 & 4 & 0 & 0 & \\
2 & 3 & 0 & 1 & 3 & 3 & 3 & & \\
3 & 3 & 1 & 3 & 0 & 4 & 0 & 0 & 0 \\
4 & 3 & 1 & 4 & 1 & 3 & 3 & 0 & 0 \\
5 & 3 & 2 & 0 & 3 & 0 & 0 & 0 & 0 \\
6 & 3 & 2 & 1 & 3 & 3 & 3 & & \\
7 & 3 & 2 & 3 & 0 & 3 & 1 & 0 & \\
8 & 3 & 3 & 1 & 1 & 3 & 0 & 0 & 0 \\
9 & 3 & 3 & 1 & 2 & 4 & 0 & 0 & 0 \\
10 & 3 & 3 & 2 & & & & & \\
11 & 3 & 3 & 2 & 3 & 3 & 3 & & \\
12 & 3 & 3 & 3 & 1 & 4 & 3 & & \\
13 & 3 & 3 & 3 & 2 & & & & \\
14 & 3 & 4 & 2 & 2 & & & & \\
15 & 3 & 4 & 2 & 2 & 4 & 0 & 0 & \\
16 & 3 & 4 & 3 & 2 & 3 & 0 & 0 & \\
\hline
\end{tabular}

\begin{tabular}{cccccccc}
\hline & \multicolumn{8}{c}{$\begin{array}{c}\text { Date } \\
\text { Plant } \\
\text { no. }\end{array}$} & 4 & 5 & 6 & 7 & 8 & 9 & 10 \\
\cline { 2 - 7 } & & $\mathbf{D}$ & & & & & \\
\hline 17 & 3 & 1 & 0 & 4 & 0 & 0 & 0 \\
18 & 3 & 2 & 1 & 0 & 0 & 0 & 0 \\
19 & 3 & 3 & & & & & \\
20 & 3 & 3 & 0 & 0 & 0 & 0 & \\
21 & 3 & 3 & 0 & 3 & 0 & 0 & \\
22 & 3 & 3 & 1 & 3 & 0 & & \\
23 & 3 & 3 & 3 & 3 & 3 & & \\
24 & 3 & 3 & 3 & 4 & 3 & 0 & 0 \\
25 & 3 & 4 & 0 & 2 & 3 & 0 & 0 \\
26 & 3 & 4 & 1 & 3 & 0 & 0 & 0 \\
27 & 3 & 4 & 1 & 3 & 2 & 0 & 0 \\
28 & 3 & 4 & 2 & 3 & 0 & 0 & 0 \\
& & & & & & & \\
29 & & 3 & 0 & 3 & 4 & 0 & 0 \\
30 & & 3 & 1 & 0 & 0 & 0 & 0 \\
31 & & 4 & 4 & 4 & 3 & 0 & 0 \\
\hline
\end{tabular}

\section{Growth rate in length}

About 10 blades were put in a glass aquarium of $30.35 .60 \mathrm{~cm}$ and were observed on fruiting and on growth. Beginning with 7 fertile blades on June 9, 1974, such an aquarium was added one by one on $10,12,13,15$, and 24 th, and they were kept outdoors with running seawater through July 6. 
Owing most probably to constant immersion, fruiting did not go with that at habitat liberating swarmers very often. It was quite common to become fertile on 2 or 3 consecutive days even during spring tides. Fruiting was not always simultaneous in one aquarium but there were some days when almost all blades in 6 aquaria became fertile. Intervals between 2 successive fruiting were averaged in each aquarium (Table $3)$. In spite of frequent fruiting and ensuring reduction in length, blades grew elomgated in the culture with some exceptions. Some were very high in growth rate and one of them reached twice as long as its starting length in 27 days, but the rates were averaged in each aquarium (Table 3).

High growth rate and frequent fruiting were closely observed with 45 clipped blades, one of which is demonstrated in Fig. 2. A fertile blade $95 \mathrm{~mm}$ long was clipped and was put in an aquarium on July 6, 1976. This piece liberated swarmers in the morning reducing length, but it grew to $95 \mathrm{~mm}$ again on the following morning ;

Table 3. Growth rate and fruiting interval of Ulva pertusa in aquaria

\begin{tabular}{|c|c|c|c|c|c|c|}
\hline \multirow{2}{*}{$\begin{array}{c}\text { Number } \\
\text { of } \\
\text { plants }\end{array}$} & \multicolumn{2}{|c|}{$\begin{array}{ll}\text { Average length } & (\mathrm{cm}) \\
\text { Start } & \text { Finish }\end{array}$} & \multirow{2}{*}{$\begin{array}{l}\text { A } \\
\text { Days } \\
\text { of } \\
\text { culture }\end{array}$} & \multirow{2}{*}{$\begin{array}{l}\text { Average increase } \\
\text { in length } \\
(\mathrm{mm} / \text { day } / \mathrm{cm}) \\
\text { MeanfS. E. }\end{array}$} & \multirow{2}{*}{$\begin{array}{l}\text { Average } \\
\text { fruiting } \\
\text { times } \\
\text { MeanfS. E }\end{array}$} & \multirow{2}{*}{$\begin{array}{c}\text { Average } \\
\text { fruiting } \\
\text { interval } \\
\text { (days) } \\
\text { MeantS. E. }\end{array}$} \\
\hline & MeantS. E. & Mean \pm S. E. & & & & \\
\hline 7 & $14.9 \pm 1.17$ & $22.0 \mathrm{f} 2.31$ & 27 & $0.20 \pm 0.080$ & $8.6 \pm 0.43$ & $3.2 \mathrm{f} 0.18$ \\
\hline 10 & $16.4 \pm 1.39$ & $22.1 \pm 1.81$ & 26 & $0.14 \mathrm{f} 0.028$ & $9.7 \pm 0.75$ & $2.9 \pm 0.30$ \\
\hline 12 & $19.5 \mathrm{f} 1.17$ & $26.4 \pm 3.88$ & 24 & $0.17 \mathrm{f} 0.080$ & $8.4 \pm 0.50$ & $3.0 \pm 0.18$ \\
\hline 10 & $20.5 \pm 1.85$ & $23.0 \pm 1.46$ & 23 & $0.08 \pm 0.041$ & $7.1 \pm 0.66$ & $3.5 \pm 0.35$ \\
\hline 10 & $14.9 \mathrm{f} 0.81$ & $23.5 \pm 2.49$ & 21 & $0.27 \mathrm{f} 0.059$ & $3.8 \pm 0.51$ & $6.2 \pm 0.65$ \\
\hline 5 & $16.7 \pm 1.87$ & $21.3 \pm 2.35$ & 12 & $0.28 \pm 0.164$ & $2.4 \pm 0.51$ & $6.2 \pm 1.56$ \\
\hline
\end{tabular}

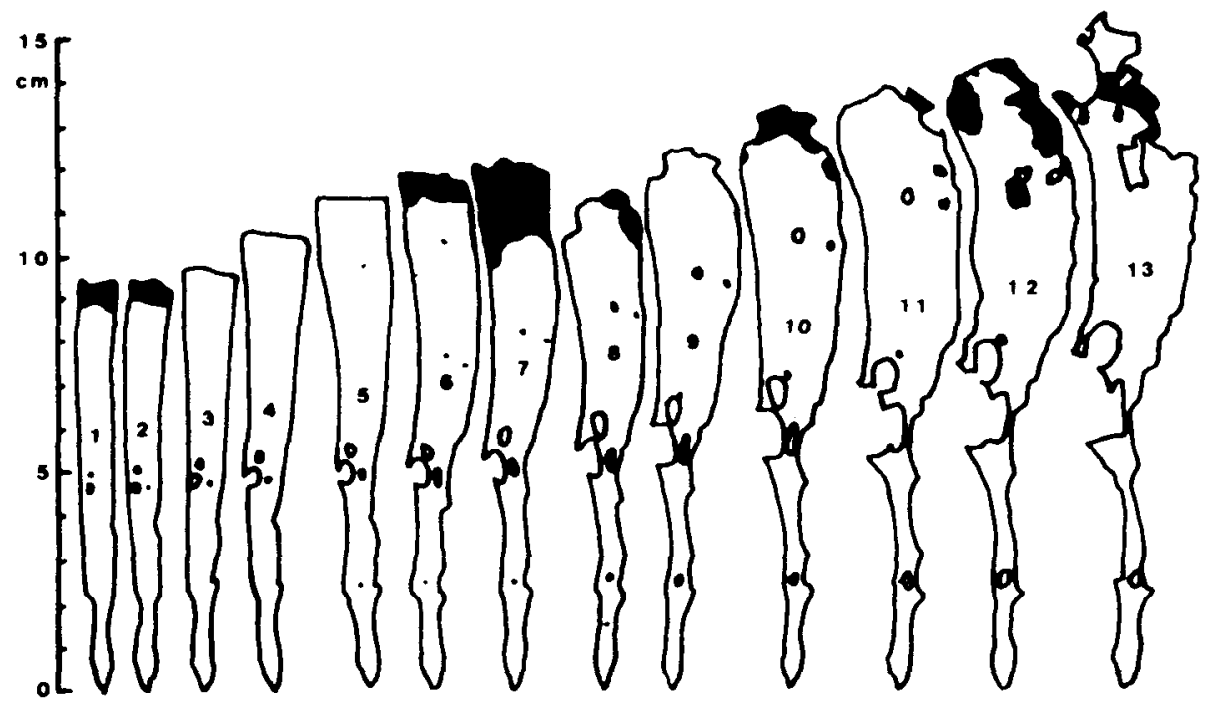

Fig. 2. Growth and fruiting of a clipped blade of Ulva pertusa in an aquarium. Dark area represents fertile. 
moreover the distal area was fertile. Four days after the last fruiting, it measured 115 $\mathrm{mm}$ and became fertile. On the following morning it was about $115 \mathrm{~mm}$ recovering length and again became fertile, that corresponded to the rank 4 in Fig. 1. After this fruiting, fertile areas were not as uniform as before or at habitat, but the piece grew longer and wider developing perforations.

There was one distinct piece that showed quite a high growth rate but did not show any sign of fruiting. Beginning with the length of $38 \mathrm{~mm}$ on July 6 , it reached 476 mm on July 26, 12.5 times longer in 20 days (Fig. 3). It also grew in width.

Tracing some natural perforations for 9 days from 9th to 18th, growth rate in length was separately obtained every day for each of 4 areas of this piece (Fig. 4). The rates were different every day even in some area, but for the basal area it stayed the same as original. A daily growth rate averaged at the distal area was $22.4 \%$, highest of all, and this area elongated 6 times. Although there were some exceptions, upper sides among the four showed higher rates in general through this period.

\section{DISCUSSION}

In the previous paper (Sawada and Watanabe, 1974), the authors reported on the development of fertile blades on several days during each neap tide series in Tsuyazaki. Fertile sporophytes appeared earlier during neap tides followed by fertile gametophytes, and the latter outnumbered the former around the quarter of the moon. After the dominancy was reversed, fertile sporophytes rapidly decreased in number and only

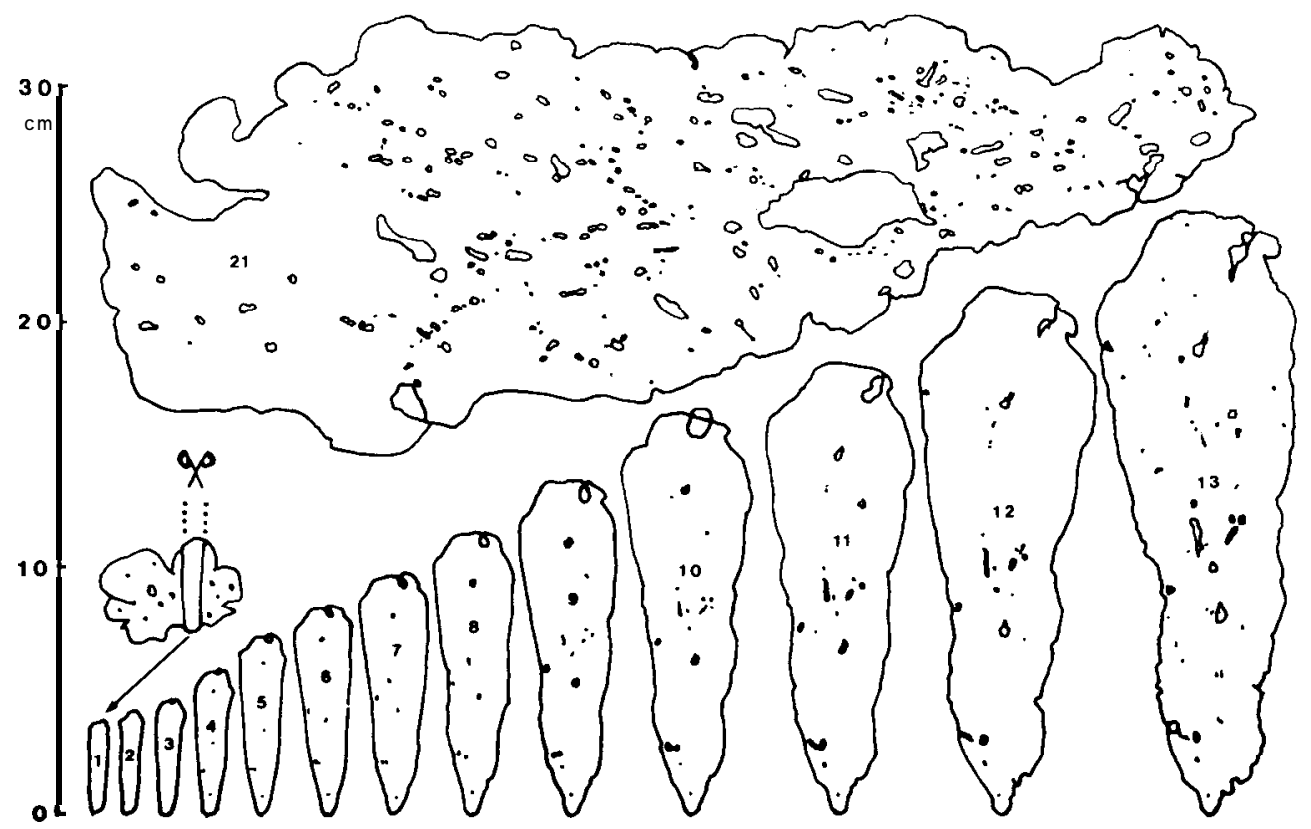

Fig. 3. Growth of a clipped sterile blade of Ulva pertusa during a 3-week culture in an aquarium. 


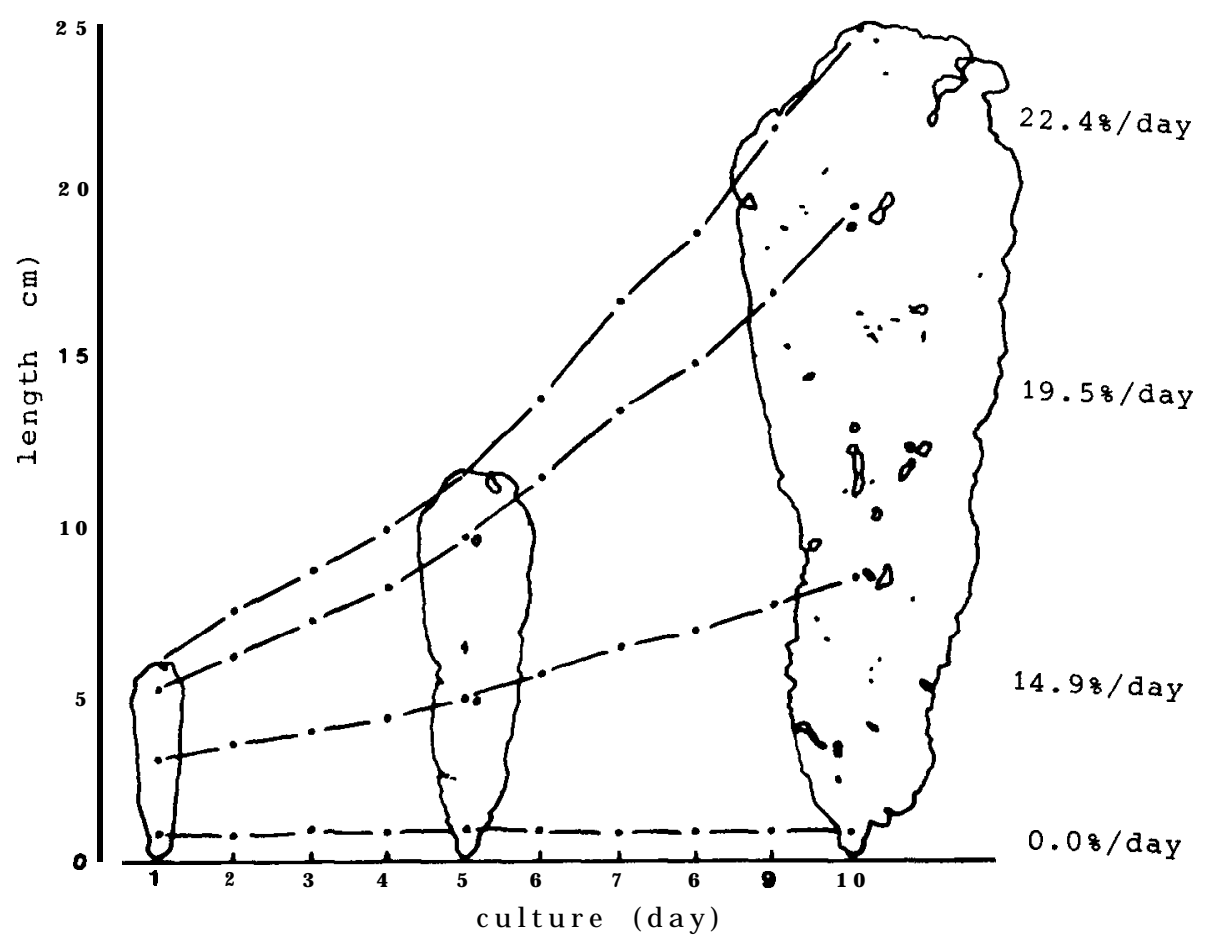

Fig. 4. Different growth rates at each of 4 parts of a clipped sterile blade of Ulva pertusa the same as in Fig. 3. Four figures on the right represent averaged daily growth rates at respective parts.

fertile gametophytes were observed late in a neap tide series in 1967 and 1969. In 1974, however, fertile sporophytes survived through neap tides with smaller amount in number along with fertile gametophytes. Observations have not been conducted since, and it remains questionable whether the fruiting pattern has changed or it has resumed the former one.

As field observations on each blade were not made in Tsuyazaki and also in Shibukawa, Okayama (Okuda, 1975), the authors had been convinced that each blade liberated swarmers once every semilunar month. As fertile areas are quite distinctive with a yellow-brown color, one blade with such conditions draws attention and only a few fertile ones seem to have lots of fertile blades. Thus the authors believed that there were still some sterile blades even when fertile ones covered the habitat. Fruiting of Ulva colonies is periodic, but, as is decisively shown in Table 2, fruiting of an Ulva blade is not fortnightly, instead it produces swarmers several times during neap tides.

Along the shores of the Monterey Peninsula, Smith (1947) reported on Ulva lobata that gametophytes and sporophytes fruit at different times in a series of spring tides. When gametophytes fruit early in a series about half the blades are sterile, and also when sporophytes fruit late in a series half the blades are sterile. Fertile gametophytes 
and sporophytes there in general appear 2 and 3 days, respectively. If each blade fruits fortnightly, one fourth of the blades comes fertile and three fourths (one fourth is gametophytes and one half is sporophytes) stay sterile one day early in the series. In the same way one sixth of the blades comes fertile and five sixths (one half is gametophytes and two thirds are sporophytes) stay sterile one day late in the series. Although Smith judged visually and did not refer to frequent reproduction in one blade, fruiting twice or thrice may well explain the situation.

Fortnightly fruiting in ulvaceous algae is reported on Ulva, Enteromorpha, and Monostroma. Fertile blades of $U$. fenestrata and $U$. scagelii (Chihara, 1968), U. arasakii (Chihara, 1969) are found for a few days, U. fasciata (Subbaramaiah, 1970) 3 days, U. pertusa (Ohno and Arasaki, 1967) several days. In E. intestinalis (Christie and Evans, 1962 ; Pandey and Ohno,1985), E. flexuosa and E. compressa (Ohno et al., 1981) and M. nitidum (Ohno, 1972) fruiting occurs not always on one particular day. As these were not the results from following each blade, previous investigators seem to be much concerned with fortnightly fruiting in each blade. However, repeated reproductions are strongly presumed.

Fruiting changed easily when blades were put in aquaria. They produced swarmers whenever during neap tides or spring tides. The fruiting interval in Table 3 is averaged in each aquarium. Other than successive-day fruiting, intervals of 3-6-day are very common and simultaneous fruiting, though not $100 \%$ among 6 aquaria, is remarkable on June 26, 30, and July 4. A 4-5-day periodicity is reported in D erbesia and Halimeda. Page and Kingsbury (1968) and Page and Sweeney (1968) showed that gamete formation in Halicystis (Derbesia) usually occurred at an interval of 4-5 days under laboratory conditions instead of biweekly in nature (Hollenberg, 1938). According to Beth (1962), field observations on Halimeda tuna in Naples showed that gametangial formation followed a $4-5-$ day periodicity. It is interesting that such a periodicity appears under conditions where tidal fluctuations are none or very little.

Growth rate is very high in this alga particularly at distal area, but not at basal area. The authors have chanced to culture a sterile plant that became 12.5 times longer in 20 days. Some beached thalli measuring about $1 \mathrm{~m}^{2}$ must have originated from such sterile ones. As the cultures were made in June and July, growth rate in winter is unknown. No blades were observed in September and October around Tsuyazaki, and each blade is still to be followed in longevity, fruiting pattern, and growth rate.

\section{ACKNOWLEDGEMENTS}

The authors are grateful to Professor Emeritus H. Tsukahara of Kyushu University for giving them every facility for this investigation through the course. They are indebted to Mr. T. Honda of the Fisheries Laboratory, Kyushu University, for his proficient assistance in preparing the equipment for cultures at the Fishery Research Laboratory, Kyushu University. The authors are also thankful to Dr. N. Mochioka, Fisheries Laboratory of Kushu University, for his valuable suggestion and help in refining Table 3.

\section{REFERENCES}

Beth, K. 1962 Reproductive phases in populations of Halimeda tuna in the Bay of Naples. Pubbl. staz.zool. Napoli, 32 (suppl) : 515-534 
Chihara, M. 1968 Field, culturing and taxonomic studies of Ulva fenestrata P. and R. and Ulva scagelii sp. nov. (Chlorophyceae) in British Columbia and Northern Washington. Syesis, 1: 87-102

Chihara, M. 1969 Ulva arasakii, a new species of green algae : its life history and taxonomy. Bull. Nat, Sci. Mus. Tokyo, 12: 849-862

Christie, A. 0. and L. V. Evans 1962 Periodicity in the liberation of gametes and zoospores of Enteromorpha intestinalis Link. Nature (Lond.), $193: 193-194$

Hollenberg, G. J. 1936 A study of Halicystis ovalis. II. Periodicity in the formation of gametes. Amer. J. Bot., 23: 1-3

Ohno, M. 1972 The periodicity of gamete liberation in Monostroma. Proc. 7th Int'l Seaweed Symp., Univ. Tokyo Press, Tokyo pp. 405-409

Ohno, M. and S. Arasaki 1967 Physiological studies on the development of the green alga - Ulva pertusa (1) Effect of temperature and light on the development of early stage. Rec. Oceanogr. Work. Japan, 9: 129-138

Ohno, M., 0. P. Mairh, V. D. Chauhan, A. Tewari, R. M. Oza, H. V. Joshi, R. S. Pandey and P. S. Rao 1981 Mass cultivation of green alga Enteromorpha on the coast of Okha, India. Rep. Usamar. biol. Inst., Kochi Univ., (3): 51-59

Okuda, T. 1975 Reproduction of ulvaceous algae with special reference to the periodic fruiting II. Fruiting of Ulva pertusa during the neap tides in Okayama. J.Fac.Agr., Kyushu Univ., 19 : 149 $-157$

Okuda, T. 1984 Reproduction of ulvaceous algae with special reference to the periodic fruiting III. Six-day periodicity in the fruiting of Ulva pertusa on the Noto Peninsula. J.Fac. Agr., Kyushu Univ., 29: 157-165

Page, J. Z. and J. M. Kingsbury 1968 Culture studies on the marine green alga Halicystis parvula Derbesia tenuissima. II. Synchrony and periodicity in gamete formation and release. Amer. J. Bot., 55: $1-11$

Page, J.Z. and B. M. Sweeney 1968 Culture studies on the marine green alga Halicystis parvula Derbesia tenuissima. III. Control of gamete formation by an endogenous rhythm. J. Phycol., $4: 253$ $-260$

Pandey, R. S. and M. Ohno 1985 An ecological study of cultivated Enteromorpha. Rep. Usa mar. biol. Inst., Kochi Univ., (7): 21-31

Sawada, T. and T. Watanabe 1974 Reproduction of ulvaceous algae with special reference to the periodic fruiting I. Semilunar rhythmicity of Ulva pertusa in northern Kyushu. J. Fac. Agr., Kyushu Univ., 18: $81-88$

Smith, G. M. 1947 On the reproduction of some Pacific coast species of Ulva. Amer. J. Bot., $34: 80$ $-87$

Subbaramaiah, K. 1970 Growth and reproduction of Ulva fasciata Delile in nature and in culture. Botanica mar., 13: 25-27 